\title{
METHODS FOR DETERMINING MOBILE LOCATION IN ZONES WITHOUT GPS RECEPTION
}

\author{
P. M. Porvatov ${ }^{1}$, pitpiter@mail.ru, \\ S. M. Elsakov ${ }^{1}$, esergeym@mail.ru. \\ ${ }^{1}$ South Ural State University, Chelyabinsk, Russian Federation.
}

The paper is devoted to methods of determination of mobile device location in zones where GPS signal does not get, using only sensors of the mobile device. Most mobile devices are completed only with GPS sensors and accelerometers. Less often mobile devices are completed with a gyroscope, a magnetic compass. The problem is to choose the best method of determination of mobile device location using only sensors of device. In reality it is not possible to use only accelerometer, gyroscope and magnetic compass, because it is necessary to calculate an object location from the already known point. The known point can be received from GPS or from points of the wireless Internet.

Keywords: location determination methods, inertial navigation, comparison of methods of location determination, determination of location in zones of GPS lack, notation of a way in the enclosed space, the accelerometer, longitude, latitude.

\section{Introduction}

The modern smart phone allows the user not only to ring and send messages, but also to go on-line, to read books, to define his location, to play games without using the button pointing device, etc. Sensors of mobile devices allow to make all listed functions. This article describes methods to determine the mobile device location in zones where there is no signal of GPS and there is no wireless internet, using an accelerometer, a gyroscope, a magnetic compass, a camera and an infrared locator. The paper does not describe methods for which in zones without GPS there are Wi-Fi points, bluetooth indicators and QR codes with coordinates of the location.

\section{Sensors of Mobile Device}

The accelerometer is a device for measurement of an proper acceleration, that is a difference between gravitational and true accelerations of object.

In case of internal state change (that is change of the mobile device acceleration), the accelerometer reports to the mobile device three values: an apparent acceleration along the OX-axis, an apparent acceleration along the OY-axis, an apparent acceleration along the OZ-axis. Fig. 1.1 shows an example of the received values of accelerometer of the mobile device lying on the desktop. It is easy to see that the force of gravity significantly affects the OZ axis and it weakly affects the axis of OX and OY, because the device lies on the desktop not ideally horizontally. Also an example shows that an acceleration has not null values. Let us refer these values to rounding error and possible external influence on the desktop or the mobile device, that is noise.

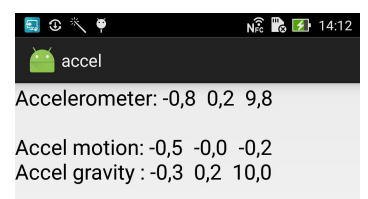

Fig. 1. The values received from the accelerometer. 
It is not necessary to calculate acceleration (further we will use not just acceleration, but a linear acceleration) from the proper acceleration, if the synthetic filter, which provides data about an acceleration, is realized in the mobile device. In case of the synthetic filter lack, it is necessary to calculate acceleration for each axis of the accelerometer by the following formulas:

$$
\begin{aligned}
& a_{x}=\hat{a}_{x}-g_{x}, \\
& a_{y}=\hat{a}_{y}-g_{y}, \\
& a_{z}=\hat{a}_{z}-g_{z} .
\end{aligned}
$$

where $a_{x}, a_{y}, a_{z}$ are accelerations (linear accelerations) along axes OX, OY, OZ, respectively; $\hat{a}_{x}, \hat{a}_{y}, \hat{a}_{z}$ are proper accelerations along axes OX, OY, OZ, respectively; $g_{x}, g_{y}, g_{z}$ are gravitation force distributed along axes OX, OY, OZ depending on a tilt angle to each axis, where

$$
g=\sqrt{g_{x}^{2}+g_{y}^{2}+g_{z}^{2}}
$$

Here $g \approx 9,80665 \frac{m}{s^{2}}$ is the free fall acceleration, which is own for each mobile device, because of accelerometer measurement errors. It is necessary to measure free fall acceleration before computation of the linear acceleration. The user shall put the mobile device on the desktop and not touch to it. If the desktop stands not exactly, then by formula (4) it is possible to calculate free fall acceleration. If the device does not include synthetic filter, which selects the linear acceleration from an apparent acceleration, then it is necessary to find device tilt angles for each axis by the following formulas:

$$
\begin{aligned}
& \alpha_{a}=\operatorname{arctg}\left(\frac{\hat{a}_{x}}{\sqrt{\hat{a}_{y}^{2}+\hat{a}_{z}^{2}}}\right), \\
& \beta_{a}=\operatorname{arctg}\left(\frac{\hat{a}_{y}}{\sqrt{\hat{a}_{x}^{2}+\hat{a}_{z}^{2}}}\right), \\
& \gamma_{a}=\operatorname{arctg}\left(\frac{\hat{a}_{z}}{\sqrt{\hat{a}_{x}^{2}+\hat{a}_{y}^{2}}}\right),
\end{aligned}
$$

where $\alpha_{a}, \beta_{a}, \gamma_{a}$ are angles of pitch, roll and yaw of the mobile device along axes OX, OY, OZ, respectively (Fig. 1.2).

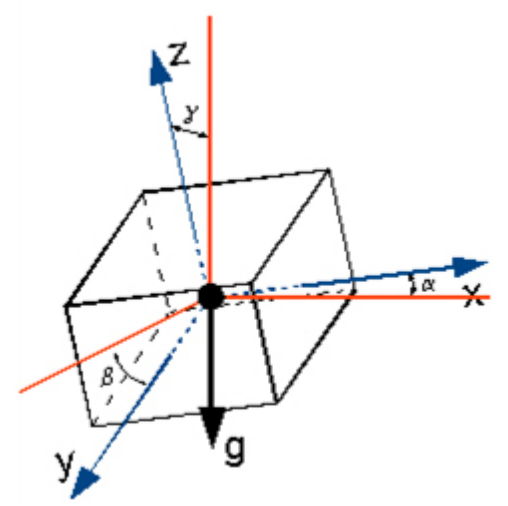

Fig. 2. Device location in the Cartesian system of coordinates. 
If the axis is perpendicular to a vector of gravity acceleration, then influence of $g$ on this axis is 0 . If the axis is parallel to a vector of gravity acceleration, then influence of $g$ on this axis is 1 . Therefore it is possible to calculate percentage influence of a gravity acceleration vector on each axis and to calculate linear acceleration:

$$
\begin{gathered}
a_{x}=\hat{a}_{x}-k_{x} g, \\
a_{y}=\hat{a}_{y}-k_{y} g, \\
a_{z}=\hat{a}_{z}-k_{z} g, \\
\sqrt{k_{x}^{2}+k_{y}^{2}+k_{z}^{2}}=1,
\end{gathered}
$$

where $k_{x}, k_{y}, k_{z}$ are relative influences of gravity acceleration $g$ on axes OX, OY, OZ, respectively.

Gyro (three axis gyro) is a device that measures the projection of the angular velocity on three axes, which are perpendicular to each other.

If an angular acceleration of the mobile device is changed, then a gyroscope reports to the mobile device three values: angular acceleration along OX axis, angular acceleration along OY axis, angular acceleration along OZ axis.

Note that coordinates axes of the mobile device move together with the device. Therefore it is necessary to calculate a device angle of rotation for each axis when using data of accelerometer and gyroscope.

The sensor of a magnetic field (compass) defines the current indications of an external magnetic field. The sensor of a magnetic field reports to the mobile device three values: value of a magnetic field along OX axis, value of a magnetic field along OY axis, value of a magnetic field along $\mathrm{OZ}$ axis.

The method of inertial navigation is used in order to find the location of the mobile device. The physical principles of inertial navigation are inseparably connected with the solution of the main problem of dynamics: it is necessary to define location of a body at a given moment by parameters and the existing data, when the body is affected by force. Coordinates of the object location are defined by length of the radius vector, the latitude and longitude in spherical system of coordinates.

Having linear acceleration of the accelerometer of the mobile device, we can define a distance between the point and the origin of coordinates:

$$
\begin{aligned}
& S_{x}=v_{x} \cdot \Delta t+\frac{a_{x} \cdot \Delta t^{2}}{2}, \\
& S_{y}=v_{y} \cdot \Delta t+\frac{a_{y} \cdot \Delta t^{2}}{2}, \\
& S_{z}=v_{z} \cdot \Delta t+\frac{a_{z} \cdot \Delta t^{2}}{2},
\end{aligned}
$$

where $S_{x}, S_{y}, S_{z}$ are distances between the point and the origin of coordinates along axes OX, OY, OZ, respectively; $v_{x}, v_{y}, v_{z}$ are constant speed of object along axes OX, OY, OZ, respectively; $a_{x}, a_{y}, a_{z}$ are linear acceleration along axes $\mathrm{OX}, \mathrm{OY}, \mathrm{OZ}$, respectively; $\Delta t$ is a time of the object acceleration.

Every time it is necessary to count the constant speed of object along OX, OY, OZ axes and to use it for calculation of the following coordinate. Note that the accelerometer 
doesn't show constant speed, it shows only an acceleration. Therefore for constant speed, for example $100 \frac{\mathrm{km}}{\mathrm{h}}$ without any acceleration, the accelerometer shows linear acceleration 0, 0, 0 (for axes OX, OY, OZ, respectively).

$$
\begin{gathered}
R=\sqrt{S_{x}^{2}+S_{y}^{2}+S_{x}^{z}}, \\
\varphi=\operatorname{arctg}\left(\frac{S_{z}}{\sqrt{S_{x}^{2}+S_{y}^{2}}}\right), \\
\lambda=\operatorname{arctg}\left(\frac{S_{y}}{S_{x}}\right)+U(\Delta t),
\end{gathered}
$$

where $R$ is a radius vector of mobile device location in spherical system of coordinates; $\varphi$ is a geocentric latitude; $\lambda$ is a geocentric longitude; $U(\Delta t)$ is an angle of earth rotation during time $\Delta t$ of the mobile device movement.

The connection between spherical and global Cartesian coordinate system is defined by formulas:

$$
\begin{gathered}
X=R \cdot \cos \varphi \cdot \cos \lambda, \\
Y=R \cdot \cos \varphi \cdot \sin \lambda, \\
Z=R \cdot \sin \varphi .
\end{gathered}
$$

where $X, Y, Z$ are coordinates of the mobile device location relative to the origin of the Cartesian coordinate system.

Intermediate points are always calculated in new system of coordinates such that an origin of new system of coordinates is the previous point.

We define the location of a new point, using coordinates of the previous point and calculating coordinates of the point relative to the origin:

$$
\begin{aligned}
X_{\text {next }} & =X_{\text {prev }}+X \\
Y_{\text {next }} & =Y_{\text {prev }}+Y, \\
Z_{\text {next }} & =Z_{\text {prev }}+Z,
\end{aligned}
$$

where $X_{\text {next }}, Y_{\text {next }}, Z_{\text {next }}$ are next coordinates of mobile device location in global Cartesian system of coordinates; $X_{\text {prev }}, Y_{\text {prev }}, Z_{\text {prev }}$ are previous coordinates of mobile device location in global Cartesian system of coordinates.

In practice, most often the object is affected by other forces (in addition to the force of gravitation), which are caused by rotation, shaking and other ways of impact on the mobile device. Note that the gravitational force is constant. Therefore any additional forces acting on the object change the accelerometer output signal, and thus there are errors of the calculations of the mobile device location. One can reduce the influence of the other forces to a minimum by preprocessing of the accelerometer output signal, but it delays issuance of the actual values. Also the quality of sensor is not the best. Therefore measurements initially have errors of offset of output values and this offset can change depending on the angle of the mobile device rotation and its location. In this case it is possible to calibrate the accelerometer and to minimize the errors. But somehow a little mistake exists and it is integrated during the process of integrating the angle and speed. In this situation, one can only assume that the user of the mobile device sometimes is in the zone of GPS signal or a wireless Internet, such as to set the original location and reset errors for calculations of next coordinates. 


\section{Improving the Method}

The above method of finding the mobile device location using only the accelerometer can be improved, if mobile device has a gyroscope. At the beginning of the article we say that if there is a change of the internal state (i.e. the change of the angular acceleration of the mobile device), then the gyroscope transmits to the mobile device the following three values: the angular acceleration on the axis OX, angular acceleration on the axis $\mathrm{OY}$, angular acceleration on the OZ axis. Using the angular acceleration, it is possible to calculate the angle of mobile device rotation for each axis:

$$
\begin{aligned}
& \alpha_{g}=\Delta t \cdot \omega_{x}, \\
& \beta_{g}=\Delta t \cdot \omega_{y}, \\
& \gamma_{g}=\Delta t \cdot \omega_{z},
\end{aligned}
$$

where $\omega_{x}, \omega_{y}, \omega_{z}$ are angular acceleration of the mobile device along OX, OY, OZ axes, respectively; $\alpha_{g}, \beta_{g}, \gamma_{g}$ are angles of the mobile device tilt along OX, OY, OZ axes, respectively.

If an accelerometer and a gyroscope are ideal, then the results of calculation of rotation angles by the formulas (5) and (24), (6) and (25), (7) and (26), respectively, are equal. Using this correspondence between calculations of angles by an accelerometer and a gyro, one can use the Kalman filter:

$$
\begin{gathered}
\alpha=K_{\alpha} \cdot \alpha_{g}+\left(1-K_{\alpha}\right) \cdot \alpha_{a}, \\
\beta=K_{\beta} \cdot \beta_{g}+\left(1-K_{\beta}\right) \cdot \beta_{a}, \\
\gamma=K_{\gamma} \cdot \gamma_{g}+\left(1-K_{\gamma}\right) \cdot \gamma_{a} .
\end{gathered}
$$

where $K_{\alpha}, K_{\beta}, K_{\gamma}$ are Kalman coefficients to calculate the angles $\alpha, \beta, \gamma$;

$\alpha, \beta, \gamma$ are angles of the mobile device tilt along OX, OY, OZ axes (Fig. 1.2).

Kalman coefficients $K_{\alpha}, K_{\beta}, K_{\gamma}$ should be in the range from 0 to 1 , and show credibility of a particular method. So, if we assume that the accelerometer is $100 \%$ wrong, then $K_{\alpha}$ is 1 , since we calculate the angle $\alpha$, using data from the gyroscope. Kalman coefficient depends on each step of calculating of the rotation angle and is not constant.

Note that the gyroscope shows the angular acceleration only at the moment of impact on the mobile device, then it is necessary to integrate the angle for each axle.

To calculate angles of the mobile device tilt it is preferable to use a gyroscope, and an accelerometer is used to calculate the distance. But even in this situation, the error increases rapidly, because an error is integrated during integrating of the angle and speed. The gyroscope has errors of a zero-drift and angular acceleration, therefore it is necessary to take into account the angle of the earth rotation during the time of the mobile device movement. Even if the errors are reduced to minimum, the integration of rotation angle quickly lead to a strong divergence of the obtained results and the actual values. 
If the mobile device has a magnetic compass, then the situation changes. The azimuth of the mobile device may be calculated by the following formula:

$$
A_{m}=\left\{\begin{array}{c}
-\frac{180}{\pi} \operatorname{arctg}\left(\frac{H_{x}}{H_{y}}\right), \text { if } H_{x}<0, H_{y}>0 \\
360-\frac{180}{\pi} \operatorname{arctg}\left(\frac{H_{x}}{H_{y}}\right), \text { if } H_{x}>0, H_{y}>0 \\
180-\frac{180}{\pi} \operatorname{arctg}\left(\frac{H_{x}}{H_{y}}\right), \text { if } H_{y}<0 \\
90, \text { if } H_{x}<0, H_{y}=0 \\
270, \text { if } H_{x}>0, H_{y}=0
\end{array} .\right.
$$

where $H_{x}, H_{y}$ are horizontal components of the earth's magnetic field along the axes OX and OY; $A_{m}$ is an azimuth of the mobile device.

If there is magnetic compass, then it is not necessary to integrate the rotation angles to find the direction of movement. But the magnetic compass is not perfect, its output data can be changed by external magnetic fields (iron doors, electrical devices, inductors). Iron objects slightly changed the magnetic field of the earth near them. Also, magnetic compass has a zero-drift error. If errors of a magnetic compass are minimized, then the total error of calculation increases only due to the accelerometer. It is so, because to calculate the mobile device location it is necessary to know the total velocity, which is obtained by integration of all velocities from an initial starting point.

Let us add a gyroscope to the accelerometer and magnetic compass and use the Kalmana filter and others filters for errors correction. Then an error increases more slowly, than errors of above methods of determining the location. But the error increases with each calculation of the current location of the point. It is possible to correct the error, if the mobile device user sometimes stops for some reason (to open the door, to drink coffee, to stand in a supermarket queue, and so on).

In addition to the above-described methods for determining the mobile device location, there is another method, the idea of which is to recognize the human step, to count the number of steps and to determine the direction of person movement.

One of the problem is to determine the step length. The step is not constant parameter, therefore its length and average step length should be calculated. Also the step length depends on the style of walking. It is necessary to calculate the average length for each walking style. The step length can be determined by the formula:

$$
L=\frac{G}{4}+0,37
$$

where $L$ is a length of a single step in meters;

$G$ is a human height in meters.

Formula (31) cannot always be used to determine a step length, but it can be used in case, when the average step length is not calculated. Average step can be calculated on interval of a way in zone of GPS.

To recognize the fact of step it is necessary to analyze the dynamic step parameters during human walking by breaking step on the phases and identifying their important parameters.

Using a point of a step emergence, its length and direction of movement, one can determine the person location. The step length depends on the walking style, and can 
be determined from output data of accelerometer. But the direction of person movement is determined only by the formulas (15) and (16). It means that there is a small error of determination of the geocentric latitude and longitude, which is given by the accelerometer. Further this error also will be integrated. But integrable error of average step will not be greatly increase, because the current step length with some frequency can be greater or less than the average step length. Also it is possible to compare parameters of phases of the current step and average step, to find a match, and thus to correct the current step length error. Note that if person moves around the building by elevator or escalator, then there is fatal error of the location determination and this method can not be used.

To determine the location one can use a mobile device camera and infrared locator that determines the exact distance between the camera and the subject. Using two photos with minimal differences (turned at a slight angle), one can identify common objects by applying of monochrome filters to photos. Next, the distance of the object offset in the photos is determined. One can calculate an angle of mobile device rotation, using the object offset in the photos and a distance to the object both for the first and the second photos.

With the help of camera one can determine the distance traveled. To this end one can use the infrared radar, if it is available for the mobile device, or to make an example of the template of object size changes depending on the distance between the object and the mobile device's camera.

Suppose there is no infrared locator. We compare two photos, which are changed by monochrome filter. Calculate the scale of the object size change and to compare it with the template. Determine the distance between the object and the camera by the template both for the first and second photos, find the difference between these distances.

If the mobile device has an infrared radar, then also two photos are compared, using monochrome filter. Then we already know the distances to the object in the photos and find the difference between these distances.

This method has no errors, which are integrated at each point of the location determination. Usually, different objects in the photo are defined at the same time. But the photos can contain objects that themselves change their location, and then the error can be catastrophic. It is also necessary to keep the mobile device in hand or fix it such that the camera can see the path in front of it, which is also not convenient for the user.

\section{Conclusion}

The method, which use accelerometer, gyroscope and magnetic compass to determine the mobile device location, can reduce the error by using the method of recognition and counting of steps. Then the accelerometer error can be reduced by using the method for step determining and Kalman filter. Sometimes the user keeps the mobile device before himself, then he can use the camera and infrared radar. Application of all methods together to determine the location can reduce the error to acceptable for navigate in zones without GPS. But the use of all methods can quickly spent a charge of the mobile device battery. Then the best variant is to use the method with an accelerometer, gyroscope and magnetic compass. 


\section{References}

1. Patent of Russian Federation №2162203. Strapdown inertial measurement unit V.M. Achil'diev, V.N. Drofa, V.M. Rublev. 2001. (in Russian)

2. Smith D.M., John M.S. Mathematical and digital modeling for engineers and researchers. Moscow, Engineering, 1980. - 271 p. (in Russian)

3. Bolshakov A.A., Karimov R.N. Methods of processing of multidimensional data and time series. Moscow, Hotline - Telecom., 2007. - 520 p. (in Russian)

4. Aleshkin M.V. Neural network modeling of excess block of accelerometers. Technical cybernetics, radio electronics and control systems: materials of the VIII All-Russia. scientific. Conf. undergraduate and graduate students. Taganrog, Taganrog. State. Radiotekhn. Univ., 2006. - P. 70. (in Russian)

5. Bromberg P.V. Theory of inertial navigation systems. Moscow, Science, 1979. - 294 p. (in Russian)

6. Jeong Won Kim. A Step, Stride and Heading Determination for the Pedestrian Navigation System. Journal of Global Positioning Systems. 2004, vol. 3, no. 1. P. 273-279.

7. Patent RU 2345326 (published on 27.01.2009), "Method for the correction of the inertial navigation system". (in Russian)

Peter M. Porvatov, Undergraduate, Institute of Natural and Exact Sciences, South Ural State University (Chelyabinsk, Russian Federation), pitpiter@mail.ru.

Sergei M. Elsakov, Candidate of Physico-Mathematical Sciences, Institute of Natural and Exact Sciences, South Ural State University (Chelyabinsk, Russian Federation), esergeym@mail.ru.

Received September 15, 2016

УДК 004.021

DOI: $10.14529 /$ jcem 160306

МЕТОДЫ ОПРЕДЕЛЕНИЯ МЕСТОПОЛОЖКНИЯ МОБИЛЬНЫХ УСТРОЙСТВ В ЗОНАХ ОТСУТСТВИЯ GPS СИГНАЛА

\section{П.М. Порватов, С.М. Елсаков}

Работа посвящена методам определения местоположения мобильного устройства в зонах, где не проникает сигнал GPS, используя только датчики мобильного устройства. Большинство мобильных устройств комплектуются только датчиками GPS и акселерометрами. Реже мобильные устройства комплектуют гироскопом, магнитным компасом. Задача состоит в том, чтобы выбрать лучший метод определения местоположения мобильного устройства используя только датчики, которыми укомплектовано устройство. В реальности использовать только акселерометр, гироскоп и магнитный компас не получится, ведь нужно вычислять положение объекта уже от известной точки. Известную точку можно получить от GPS или от точек беспроводного интернета.

Ключевые слова: методы определения местоположения, инериионная навигаиия, сравнение методов определения местоположения, определение местоположения в зонах отсутствия GPS, счисление пути в закрытых помещениях, акселерометр, долгота, широта. 


\section{Литература}

1. Патент РФ №2162203. Бесплатформенный инерциальный измерительный блок / В.М. Ачильдиев, В.Н. Дрофа, В.М. Рублев. 2001.

2. Смит, Д.М. Математическое и цифровое моделирование для инженеров и исследователей / Джон М.С. - М.: Машиностроение, 1980. - 271 с.

3. Большаков, А.А. Методы обработки многомерных данных и временных рядов: учеб. пособие / А.А. Большаков, Р.Н. Каримов. - М.: Горячая линия - Телеком, 2007. - $520 \mathrm{c}$.

4. Алешкин, М.В. Нейросетевое моделирование избыточного блока акселерометров / М.В. Алешкин // Техническая кибернетика, радиоэлектроника и системы управления: материалы VIII Всерос. науч. конф. студентов и аспирантов. - Таганрог: Таганрог. гос. радиотехн. ун-т, 2006. - С. 70.

5. Бромберг, П.В. Теория инерциальных систем навигации / П.В. Бромберг. М.: Наука, 1979. - 294 с.

6. A Step, Stride and Heading Determination for the Pedestrian Navigation System, Jeong Won Kim, Journal of Global Positioning Systems. - 2004. - V. 3, № 1. P. 273-279.

7. Патент RU 2345326 (опубликовано 27.01.2009), "Способ коррекции инерционной навигационной системы".

Порватов Петр Михайлович, магистр, Институт естественных и точных наук, Южсн-Уральский государственный университет, (ә. Челябинск, Российская Федераuия),pitpiter@mail.ru

Елсаков Сергей Михайлович, кандидат фикико-математических наук, Институт естественных и точных наук, Южсн-Уральский государственный универсиmет, (ә. Челябинск, Российская Федерачия), еsergeym@таil.ru

Поступила в редакиию 15 сентября 2016 г. 